\title{
Applying the Extended Theory of Planned Behavior to Predict Collaborative Consumption Intentions
}

\begin{abstract}
In this study we test and validate theory of planned behavior (TPB) to predict consumers' collaborative consumption intentions. In addition, we extend the TPB by studying consumers' price consciousness as a potential determinant of collaborative consumption intentions. The empirical data is based on the survey study that was conducted in Finland in 2015. Our main findings are as follows. First, our study indicates that consumers' attitudes towards collaborative consumption are positively related to their intentions to participate in collaborative consumption. Second, our study reveals that subjective norm is positively related to consumers' collaborative consumption intentions. Our results also demonstrate that if consumers have the abilities to engage in collaborative consumption, it enhances their intention to participate in such behavior. As a final contribution, our study indicates that price consciousness acts as determinant for taking part in collaborative consumption. Overall, our results are consistent with the TPB. Based on our study, it can be argued that TPB is a useful theoretical framework to investigate the motivations among consumers to engage in collaborative consumption.
\end{abstract}

Key words: sharing economy, collaborative consumption; theory of planned behavior

Author 1

Name: Arto Lindblom

Department: Department of Marketing University: Aalto University, School of Business

City: Helsinki

Country: Finland

Postal address: P.O. Box 21210, FI-

00076 AALTO, FINLAND

Email: arto.lindblom@aalto.fi
Author 2

Name: Taru Lindblom

Faculty: Faculty of Social Sciences, Sociology

University: University of Tampere

City: Tampere

Country: Finland

Postal address: Faculty of Social

Sciences, Sociology, 33014 University

of Tampere, FINLAND

Email: taru.lindblom@uta.fi 


\section{Introduction and purpose}

The 'sharing economy' is spreading rapidly and has transformed people's ways of thinking about ownership and consuming. Matzler et al. (2015, p. 71) highlight this change in people's minds and behavior, stating that "While individuals have traditionally often seen ownership as the most desirable way to have access to products, increasing numbers of consumers are paying to temporarily access or share products and services rather than buy or own them." In a similar vein, Bardhi and Eckhardt (2012) state that consumers now want access to products, and they prefer to pay for the experience of using the object than to buy and own it (see also Watkins et al., 2016; Lindblom and Lindblom, 2017).

In short, the 'sharing economy' is the idea of sharing of resources between individuals who have access to goods as needed. Belk (2007, p. 126) has defined sharing "as the act and process of distributing what is ours to others for their use and/ or the act or process of receiving or taking something from others for our use". Bardhi and Eckhardt (2012) argue that sharing is a mode of behavior that does not involve a transfer of ownership. Anyone can share almost anything: material goods, time, ideas, skills and competencies. In practice, sharing can include car-pooling, space-sharing or couch surfing.

Perhaps the best-known form of sharing is collaborative consumption. Botsman (2013) defines collaborative consumption as "an economic model that is based on sharing, swapping, trading, or renting products and services" (see also Botsman and Rogers, 2010). Belk (2014) makes an important distinction 
between collaborative consumption and other forms of sharing by defining collaborative consumption as a behavior where people coordinate the acquisition and distribution of resources for a fee or other compensation. One practical example of collaborative consumption is peer-to-peer renting (see e.g. Philip et al., 2015).

Nowadays, there are several business ventures and startups that have boosted collaborative consumption to rapid growth by creating online-based platforms or marketplaces. Well-known examples of such ventures include Airbnb, an online accommodations marketplace, and Uber, a transportation network company. There are also many $\mathrm{C} 2 \mathrm{C}$ platforms such as Mercari and Rakuma that focus on the collaborative consumption of second-hand or vintage goods. These new business models have gained a lot of interest among researchers and practitioners as well (see e.g. Van Alstyne et al., 2016).

A growing body of research has extended our knowledge of the popular movement of collaborative consumption (see e.g. Hamari et al., 2016). Researchers have tried to specify the reasons for participation in collaborative consumption, and how collaborative consumption varies across various groups (see e.g. Möhlmann, 2015; McArthur, 2015; Philip et al., 2015). For example, Möhlmann (2015) showed that consumers engage in collaborative consumption for rational reasons. In their report, Owyang et al. (2014) indicated that younger people are much more likely to engage in collaborative consumption than older people. In addition, Owyang et al. (2014) found a small gender gap in 
collaborative consumption in that women are slightly more likely than men to engage in collaborative consumption.

In order to expand the collaborative consumption to a broader mass of consumers and to develop new kinds of commercial platforms, researchers and practitioners require more knowledge and understanding about the motivating factors to engage in collaborative consumption (see e.g. Akbar et al., 2016). The theory of planned behavior (TPB) offers an interesting framework to examine the factors that are related to consumers' intentions to engage in collaborative consumption. TPB proposes that consumers' intentions can best be predicted by their attitudes, subjective norms, and perceived behavioral control (Ajzen, 1991; 2005). To our knowledge, no prior academic research has used TPB to investigate the determinants of collaborative consumption. Against this backdrop, we test and validate TPB to predict consumers' collaborative consumptions intentions. In addition, we extend the TPB by studying consumers' price consciousness as a potential determinant of collaborative consumption intentions. Previous studies have indicated that this factor may have great impact on consumers' participation in collaborative consumption (e.g. Möhlmann, 2015; Philip et al., 2015).

To be more specific, we focus on the following questions:

1. How are consumers' attitudes towards collaborative consumption related to their intentions to engage in collaborative consumption? 
2. How are subjective norms related to consumers' intentions to engage in collaborative consumption?

3. How is consumers' perceived behavior control related to their intentions to engage in collaborative consumption?

4. How is consumers' price consciousness related to their intentions to engage in collaborative consumption?

5. How do these potential determinants (i.e. attitudes, subjective norms, perceived behavioral control, and price consciousness) and collaborative consumption intentions vary among certain demographic groups?

By studying these questions, we contribute the consumer research in general, and to the sharing economy and collaborative consumption literature in particular. Also, we aim to provide new insights for practitioners to develop and promote their platforms or marketplaces in the area of sharing of economy.

\section{Theoretical background}

The theory of planned behavior (TPB), developed by Ajzen and Fishbein (1980) and Ajzen (1991), has proved useful in understanding a wide variety of individual behaviors (see e.g. Eddosary et al., 2015; Paul et al., 2016). TPB has been tested and validated in settings, including blood donation, healthy eating, green product consumption, digital piracy and alcohol use (see e.g. Armitage and Conner, 2001; Netemeyer and Bearden, 1992; Paul et al., 2016). 
TPB is an extension of Fishbein's theory of reasoned action (TRA) (Fishbein \& Ajzen, 1975). According to Dutta and Singh (2014), both models were designed to explain the factors that influenced behavior. The difference between these two models is that TRA (Fishbein and Ajzen, 1975) does not include perceived behavioral control, and thus is not designed to predict behaviors that are outside an individual's volitional control (Hassan et al., 2016).

A key factor in TPB is the individual's intention to perform a given behavior. In short, intentions are assumed to capture the motivational factors that affect the behavior in question (Ajzen, 1991). Ajzen (1991, p. 181) argues that intentions are "indications of how hard people are willing to try, of how much of an effort they are planning to exert, in order to perform the behavior." In a similar vein, Dutta and Singh (2014) define intentions as individual's conscious motivation to make an effort to engage in the specific behavior. Ajzen (1991, p. 181) states that "the stronger the intention to engage in a behavior, the more likely its performance". In other words, intention is a reliable predictor of actual behavior although the relationship between intention and behavior is not perfect (Ajzen, 1991, 2005; Yunhi and Heesup, 2010).

According to TPB, intention has three antecedents (Ajzen, 1991; Hrubes and Ajzen, 2001; see also Ajzen, 2005):

- Attitude towards behavior: the degree to which individual has a favorable (or unfavorable) assessment or appraisal of the behavior in question. 
- Subjective norms: perceived social pressure to perform (or not to perform) the behavior in question.

- Perceived behavioral control: perceived ease (or difficulty) of performing the behavior in question.

In short, TPB suggests that individual's attitude toward the behavior in question, individual's perception of whether peer group or other significant others want him/her to perform the behavior, and individual's perceived ability to do so will predict his/her intention to undertake the behavior (Ajzen, 1991; 2005).

\section{Research hypotheses}

Attitude towards the behavior, the first determinant of intention, can be defined as an individual's favorable or unfavorable assessment of the behavior under consideration (Ajzen, 1991; 2005; Lee et al., 2009). In other words, attitude refers to judgment on whether the behavior in question is good or bad, and whether the individual wants to engage in such behavior (see e.g. Dutta and Singh, 2014). As Ajzen (1991) has stated, the more favorable the attitude with respect to the behavior under consideration, the stronger should be an individual's intention to perform that behavior. Therefore, we can assume that if consumers have a favorable perception of collaborative consumption, they probably have a high intention to engage in such behavior. In other words, based on TPB, we predict the following: 
H1: Favorable attitude towards collaborative consumption is positively related to consumers' intention to engage in collaborative consumption.

The second determinant of intention in the TPB is subjective norm. In short, subjective norms refer to an individual's estimate of the social pressures on him/ her to engage (or not) in the behavior under consideration (Ajzen, 1991; 2005; Dutta and Singh, 2014; Yunhi and Heesup, 2010; Paul et al., 2016). According to Marta et al. (2014, p. 199) subjective norms are "a function of the person's beliefs regarding what each referent thinks he or she should do and the motivation to comply with these referents". Although perceived social pressure may significantly affect a consumer's intentions to undertake specific behavior, it has been argued that the predictive power of subjective norms is sometimes low (Ajzen, 1991; Lee et al., 2009; Paul et al., 2016). In this study, subjective norms are perceived social pressure to engage in collaborative consumption. Based on TPB, we predict the following:

H2: Subjective norms supporting collaborative consumption are positively related to consumers' intention to engage in collaborative consumption.

The third predictor of intention in the TPB is perceived behavioral control. In short, perceived behavioral control is "an individual's perception of the ease or difficulty of conducting the behavior" (Ajzen, 1991, p. 183; see also 2005). Marta et al. (2014) argue that perceived behavior control address people's perceptions of their ability to perform a given behavior. Ferdous (2010), in turn, states that perceived behavioral control reflects past experiences and anticipated obstacles. 
According to Hansen (2008), a person is more likely to carry out a behavior if he or she perceives that carrying out such behavior is easy. Paul et al. (2016) state that several studies have shown that perceived behavioral control is positively linked with intention in various contexts. In this study, perceived behavior control refers to whether consumers have the abilities to engage in collaborative consumption. Based on TPB, we predict the following:

H3: Perceived behavioral control is positively related to consumers' intention to engage in collaborative consumption.

It is widely argued that for many consumers saving money is one of the key reasons to engage in collaborative consumption. For example, Möhlmann (2015) showed that consumers engage in collaborative consumption mainly for rational reasons. According to Möhlmann (2015), consumers pay attention to the fact that collaborative consumption is a way to help them to save money. Philip et al. (2015) also found that people engaged in peer-to-peer renting for economic pursuits, to maximize savings and earnings. Owyang et al. (2014) revealed that for many consumers the reason for collaborative consumption is price. Although there are also some contradictory results (Moeller and Wittkowski, 2010), it can be assumed that consumers' price consciousness can be a significant antecedent of collaborative consumption. Price consciousness refers to the importance that consumers give to price when evaluating or purchasing products (Lichtenstein et al., 1988; Lichtenstein et al., 1993). To be more specific, we predict the following: 
H4: Price consciousness is positively related to consumers' intention to engage in collaborative consumption.

\section{Methodology}

\section{Sample}

The sample was drawn from the adult population of Finland (mainland). The sample thus is nationally representative. A total of 3500 questionnaires and self-addressed pre-paid envelopes were mailed to Finnish citizens. Of these, 976 (27.9\%) usable responses were returned. Table 1 lists the demographic details of the respondents.

\section{INSERT TABLE 1 AROUND HERE}

\section{Measures}

Collaborative consumption intentions

Intentions are consumers' aim to carry out and engage in collaborative consumption in the future (see e.g. Azjen, 1991; 2005). Based on this definition, we developed two items to measure collaborative consumption intentions:

- I have an intention to increase collaborative consumption in the near future. 
- Collaborative consumption will not be a central part of my consumption in the future (reverse).

Both items were measured on a 7-point scale and these items exhibited a reliability of 0.673 .

As the terminology of collaborative consumption is not very established in Finland, a short introductory text explaining to respondents what is referred to by the concept of collaborative consumption was provided in the questionnaire. Examples of such behavior and the marketplaces where they take place were provided. In the questionnaire we used a Finnish word that refers to peer-topeer consumption or trade.

Collaborative consumption attitudes

Collaborative consumption attitudes are the extent to which someone perceives collaborative consumption as favorable or unfavorable (Ajzen, 1991; 2005; Lee et al., 2009). Based on this definition, we developed two items to measure collaborative consumption attitudes:

- I have favorable attitude towards collaborative consumption.

- Collaborative consumption is a smart way to acquire and sell the goods.

Both items were measured on a 7-point scale and exhibited a reliability of 0.916 . 
Subjective norms

Subjective norms are perceived social pressure to engage in collaborative consumption (Ajzen, 1991; 2005). Based on this definition, we developed two items to measure subjective norm:

- My friends or family members have made me interested in collaborative consumption.

- Many of my close friends have engaged in collaborative consumption.

Both items were measured on a 7-point scale and exhibited a reliability of 0.736 .

Perceived behavioral control

Perceived behavior control is whether consumers have the abilities to engage in collaborative consumption (Ajzen, 1991; 2005). Based on this definition, we developed two items to measure perceived behavioral control:

- Acquiring and selling the goods by engaging in collaborative consumption is simple

- Collaborative consumption is uneasy way to acquire and sell the goods (reverse).

Both items were measured on a 7-point scale and exhibited a reliability of 0.713 . 
Price consciousness

Price consciousness is the degree to which consumers focus on paying low prices (Lichtenstein et al., 1988; Lichtenstein et al., 1993). Based on current literature on price consciousness, we utilized the following items in measuring price consciousness (see Kopalle and Lindsey-Mullikin 2003; Kukar-Kinney et al., 2012):

- I check the prices even for inexpensive items before buying.

- Low price is an important consideration in my purchases.

- No matter what I buy, I shop around to get the lowest price.

- I am not willing to make extra effort to find lower prices (reverse).

All items were measured on a 7-point scale and exhibited a reliability of 0.690 .

Gender had values (1) female and (2) male.

Age was measured as continuous variable (year of birth) that was categorized to six age groups: a) under 26, b), 26-35, c) 36-45, d) 46-55, e) 56-65, and f) over 65. It should be noted that there was a substantial share of missing values for age $(13.4 \%)$.

Employment status had seven categories: a) employed, b) unemployed or seeking for a job, c) entrepreneur, partner in a company, or freelancer, d) student, e) retired, and f) other. 
Education indicated respondent's highest level of education and had the following categories: a) primary/ comprehensive school, b) vocational school, c) matriculation (upper secondary school), d) university/ polytechnic, e) academic postgraduate diploma.

Income was measured as total monthly gross income of the household. The initial categorization had 10 categories at roughly 1000-euro intervals (the median income category was 3901-4900€), but for the analyses, the income brackets were recoded to approximate income quartiles. The income quartile categories are thus: a) 2900 euros or less, b) 2901 to 3900 euros, c) 3901 euros to 5900 euros, d) over 5900 euros. Since the original measure was categorized, the quartiles produced are approximate.

\section{Data analysis}

Data analysis is executed in two parts. The first part of the data analysis utilizes analysis of variance (ANOVA) to test the differences between certain demographic groups across collaborative consumption attention (CCA), subjective norm $(\mathrm{SN})$, perceived behavioral control (PBC), price consciousness (PC) and collaborative consumption intentions (CCI). The second part presents regression-based prediction models using $\mathrm{CCA}, \mathrm{SN}, \mathrm{PBC}$ and $\mathrm{PC}$ as independent variables and CCI as the dependent variable. 
The first stage of the data analysis used the ANOVA technique to compare the CCA, SN, PBC, PC and CCI across several demographic groups. In Table 2, we present the means, F-values and p-values produced by the ANOVA procedure.

\section{INSERT TABLE 2 AROUND HERE}

As can be seen in Table 2, Finnish consumers have very positive attitudes towards collaborative consumption. On the average the respondents exhibited high interest in collaborative consumption in form of attitudes (mean 5.36). The

intentions to participate in collaborative consumption were not as high, though; mean being somewhat lower at 4.08 . The means for other constructs were rather similar with CCI; means hovered around 4, indicating a rather neutral perception on $\mathrm{SN}, \mathrm{PBC}$ and $\mathrm{PC}$.

The impact of the background variables varied greatly across the studied constructs. Age had clearly strongest effect in most cases. Collaborative consumption attitude was clearly highest in the age bracket 26 to 35. This age group had also highest scores for subjective norm. Perceived behavioral control was even across the age groups except for those over 65 who had significantly lower scores than the others. PC was highest among the youngest cohort and lowest among 36- to 45-year-olds. Collaborative consumption intention was highest for those less than 45 years old.

From a gender perspective, female consumers' intentions were more collaborative, both in terms of their attitudes and their intentions. Women also 
had slightly higher scores for subjective norm, whereas there was no statistical significance between the genders for their perception of behavioral control or price consciousness.

Employment status had a significant effect on the studied constructs. Respondents on parental leave had most positive attitudes and intentions towards collaborative consumption and highest scores for $\mathrm{SN}$ and PBC, whereas the retired proved to be their complete opposites. The CCA of entrepreneurs and unemployed were similar, although the intentions to participate in collaborative consumption set them apart (entrepreneurs being less eager). PC was lowest among the entrepreneurs and highest among students, the unemployed and those on parental leave. This is quite likely an effect of income.

Education had an effect all but one construct (PBC). The effect size of education was rather modest, being strongest for CCA. CCA was clearly lowest among those with only basic education, and highest for university graduates. Interestingly enough the former and those with postgraduate degree also had the lowest scores for CCI. The holders of postgraduate degrees had the lowest scores for SN and $\mathrm{PC}$ across the education groups. The most PC groups were those with basic education and those with upper secondary degrees.

Predictably, income had the greatest impact on price consciousness. Income showed no statistical significance for SN, PBC and CCA. A moderate effect was found between CCI and income: the higher income groups had more positive attitudes towards collaborative consumption. 
The second stage proceeded with the analysis of the linear association by using regression analysis. Regression equations were developed to determine the relationship between the respondents' intentions towards collaborative consumption (CCI) and CCA, SN, PBC and PC. Table 3 shows the equations presenting regression coefficients, F-values, significance ( $p$ ) and coefficient of determination (adjusted R2).

\section{INSERT TABLE 3 AROUND HERE}

There are three conclusions to be derived from Table 3. First, all the studied constructs but price consciousness have a substantial impact on CCI. This indicates that contrary to the previous assumptions in the literature, lower price is not a major motive for taking part in collaborative consumption. Second, each studied construct has a positive (linear) relationship with the CCI. Increase in scores for CCA, SN, PBC and PCincrease the values of CCI. Third, the constructs CCA, SN and PBC each have a rather strong independent effect on CCI. This can be seen in models 1-3, where the effect of each construct remains even when controlling for another variable.

All constructs with the exception of PC explain a substantial share of the variation in CCI ( $\mathrm{R} 2$ coefficients ranging from 27.6 to 30.1 ). As there is only a minor increase of R2 from the baseline model (unadjusted effects) to models 13, the CCI can be well explained by each individual construct. However, the CCI can be assumed to be highest among those who perceive their behavioral control 
to be high and who have positive attitudes towards collaborative consumption (as shown by model 2 in Table 3).

Thus, all four hypotheses were supported. First, support for H1 was found as CCA was positively related to CCI (standardized beta coefficient was positive at 0.53 ). Second, SN was positively related to consumer's intention to participate in collaborative consumption (standardized beta 0.55 ) thereby, supporting H2. Third, there was a statistically significant association between PBC and CCI (standardized beta 0.55$)$ so $\mathrm{H} 3$ was supported. Finally, PC was positively related to $\mathrm{CCI}$ (standardized beta 0.17) although the effect remained rather weak. Therefore we can also say H4 is confirmed but with some caution. In addition we found that each of these hypotheses work well alone, as there was no significant change in the models where several constructs were introduced. It means they can predict collaborative consumption intentions very well independently.

\section{Conclusion and discussion}

In past few years there have emerged several studies that have extended our knowledge of the sharing economy and growing movement of collaborative consumption (see e.g. Belk, 2014; McArthur, 2015; Möhlmann, 2015; Lindblom and Lindblom, 2017). In particular, various sharing platforms and marketplaces have gained a lot of interest among researchers and practitioners (see e.g. Van Alstyne et al., 2016). Although there is an increasing interest towards sharing economy and collaborative consumption, there is great need for further research. Especially, there is a lack of understanding of the factors that affect consumers' 
intentions to engage in collaborative consumption. Against this background, our aim was to further increase understanding of determinants of collaborative consumption intentions. In addition, we analyzed how these determinants and intentions vary among certain demographic groups.

Based on our analyses and the sample of 976 Finns, our study offers the following substantive contributions.

As a first contribution, our study indicates that consumers' attitudes towards collaborative consumption are positively related to their intentions to participate in collaborative consumption. In other words, consumers who have favorable perception of collaborative consumption also have strong intentions to engage in collaborative consumption. While this result is more or less intuitive, it is well in line with the previous research that attitudes are one of the most important predictors of behavioral intentions (Ajzen, 1991; 2005; see also Eddosary et al., 2015; Paul et al., 2016; Stanislawski et al., 2013).

As a second contribution, we demonstrated that subjective norm is positively related to consumers' intentions to engage in collaborative consumption. In other words, consumers are willing to perform collaborative consumption if they perceive that their significant others prefer this kind of behavior. This is a theoretically interesting finding because many of the previous studies have indicated that subjective norm has a very weak or even an insignificant link to intention (Ajzen, 1991; Stanislawski et al., 2013; Paul et al., 2016). However, it 
seems that in the context of collaborative consumption, subjective norm is an important determinant of consumers' intentions.

As a third contribution, we confirmed that there is a straightforward relationship between perceived behavioral control and intentions. Our results demonstrated that if consumers have the ability to engage in collaborative consumption, it enhances their intention to participate in such behavior. Therefore, one could argue that in encouraging consumers to engage in collaborative consumption, it is important to enhance consumers' perceived behavioral control. By doing this, consumers' willingness to join in collaborative consumption could increase significantly. At the same time, it can be assumed that digitalization has already removed many obstacles to engaging in collaborative consumption.

As a final contribution, our study demonstrated that price consciousness is a determinant of collaborative consumption intentions. However, this link was relatively weak, and it might indicate that lower price may not be the key motive for taking part in collaborative consumption.

We also looked at how the determinants and intentions vary among demographic groups. Generally speaking, it seems that young and highly educated female consumers are most inclined to engage in collaborative consumption; elderly males with basic education and low income are less interested in collaborative consumption. These findings are well in line with results presented by Owyang et al. (2014). 
For practitioners the results in this study have revealed interesting insights into Finnish consumers from collaborative consumption perspective. In particular, this study has increased the understanding of the determinants of collaborative consumption intentions. In short, these results could useful for the companies that are planning to engage in online-based platforms or marketplaces in the area of sharing of economy.

\section{Limitations and future research}

There are some limitations that suggest caution in assessing our findings.

First, our study considered collaborative consumption in general, and therefore, findings may be different if specific collaborative consumption behaviors or contexts are considered. Future research should test and validate TPB in a variety of settings, such as peer-to-peer renting or car-pooling.

Second, this study used a cross-sectional design. Therefore, it is difficult to establish causality between studied factors. In fact, in cross-section analyses causality is often open to debate. However, to overcome this problem, future studies should employ longitudinal data to establish causality.

In addition, future studies should use more advanced analysis techniques such as structural equation modelling (SEM) to determine relationships between studied factors. Moreover, we argue that there is also a need for qualitative empirical studies to obtain a clearer understanding of collaborative consumption practices. 
These in-depth qualitative studies could reveal issues that would enable more thorough operationalization of the concepts linked to collaborative consumption. 


\section{References}

Ajzen, I. (1991) The theory of planned behavior. Organizational Behavior and Human Decision Processes, 50, 179-211.

Ajzen, I. (2005) Attitudes, Personality, and Behavior, 2nd edn. Open University Press and McGraw-Hill, Inc., Berkshire.

Ajzen, I., \& Fishbein, M. (1980) Understanding attitudes and predicting social behavior. Englewood Cliffs, NJ: Prentice Hall.

Akbar, P., Mai, R., \& Hoffmann, S. (2016). When do materialistic consumers join commercial sharing systems. Journal of Business Research, 69(10), 4215-4224.

Armitage, C. \& Conner, M. (2001) Social Cognitive Determinants of Blood Donation, Journal of Applied Social Psychology, 31, 1431-1457.

Bardhi, F. \& Eckhardt, G. (2012) Access-Based Consumption: The Case of Car Sharing. Journal of Consumer Research, 39, 881-898.

Belk R. (2014) You are what you can access: sharing and collaborative consumption online. Journal of Business Research, 67, 1595-1600. 
Botsman, R. (2013) The Sharing Economy Lacks a Shared Definition. Co.Exist, November 21. http://www.fastcoexist.com/3022028/the-sharing-economy-lacks-ashareddefinition\#4.

Botsman R. \& Rogers R. (2010) What's mine is yours-the rise of collaborative consumption. HarperCollins: NY.

Dutta, K. \& Singh, S. (2014) Applying the Theory of Planned Behavior to Understand Indian Housewives' Purchase Behavior Towards Healthy Food Brands. Journal of Brand Management, 11, 7-28.

Eddosary, M., Yong, J., Sagas, M. \& Hee Y. (2015) Consumers' intention to attend soccer events: Application and extension of the theory of planned behavior. Psychological Reports, 117, 89-102.

Ferdous, A. (2010) Applying the Theory of Planned Behavior to Explain Marketing Managers' Perspectives on Sustainable Marketing. Journal of International Consumer Marketing, 22, 313-325.

Fishbein, M., \& Ajzen, I. (1975) Belief, attitude, intention, and behavior: an introduction to theory and research. Reading, MA: Addison-Wesley.

Hamari, J., Mimmi Sjöklint,, M. \& Ukkonen, A. (2016) The sharing economy: Why people participate in collaborative consumption. Journal of the Association for Information Science and Technology. 67, 2047-2059. 
Hansen, T. (2008) Consumer values, the theory of planned behaviour and online grocery shopping. International Journal of Consumer Studies, 32, 128-137.

Hassan, L., Shiu, E. \& Parry, S. (2016) Addressing the cross-country applicability of the theory of planned behaviour (TPB): A structured review of multi-country TPB studies. Journal of Consumer Behaviour, 15, 72-86.

Hrubes, D. \& Ajzen, I. (2001) Predicting Hunting Intentions and Behavior: An Application of the Theory of Planned Behavior. Leisure Sciences, 23, 165-178.

Kopalle, P. \& Lindsey-Mullikin, J. (2003) The Impact of External Reference Price on Consumer Price Expectations. Journal of Retailing, 79, 225-236

Kukar-Kinney, M., Ridgway, N. \& Monroe, K. (2012) The Role of Price in the Behavior and Purchase Decisions of Compulsive Buyers. Journal of Retailing, 88, 6371.

Lee, R., Murphy, J. \& Swilley, E. (2009) The moderating influence of hedonic consumption in an extended theory of planned behavior. Service Industries Journal, 29, 539-555.

Lichtenstein, D., Bloch, P. \& Black, W. (1988) Correlates of Price Acceptability. Journal of Consumer Research, 15, 243-252. 
Lichtenstein, D., Bloch, P., Black, W., Ridgway, N. \& Netermeyer, R. (1993) Price Perceptions and Consumer Shopping Behavior: A Field Study. Journal of Marketing Research, 30, 234-245.

Lindblom A., \& Lindblom T. (2017) De-ownership orientation and collaborative consumption during turbulent economic times. International Journal of Consumer Studies, 41:431-438.

Marta, E., Manzi, C., Pozzi, M. \& Vignoles, V. (2014) Identity and the Theory of Planned Behavior: Predicting Maintenance of Volunteering After Three Years. Journal of Social Psychology, 154, 198-207.

Matzler, K., Veider, V. \& Kathan, W. (2015) Adapting to the Sharing Economy. MIT Sloan Management Review, 56, 71-77.

McArthur, E. (2015) Many-to-many exchange without money: why people share their resources. Consumption, Markets \& Culture, 18, 239-256.

Moeller S. \& Wittkowski K. (2010) The burdens of ownership: reasons for preferring renting. Managing Service Quality, 20, 176-191.

Moons, I. \& De Pelsmacker, P. (2012) Emotions as determinants of electric car usage intention. Journal of Marketing Management, 28, 195-237. 
Möhlmann, M. (2015) Collaborative consumption: determinants of satisfaction and the likelihood of using a sharing economy option again. Journal of Consumer Behaviour, 14, 193-207.

Netemeyer, R. \& Bearden, W. (1992) A comparative analysis of two models of behavioral intention. Journal of the Academy of Marketing Science, 20.

Owyang J, Samuel A, Grenville A. (2014) Sharing is the new buying. Available online: www.web-strategist.com (last access December 03, 2014).

Paul, j., Modi, A. \& Patel, J. (2016) Predicting green product consumption using theory of planned behavior and reasoned action. Journal of Retailing \& Consumer Services, 29, 123-134.

Philip, H., Ozanne, L. \& Ballantine, P. (2015) Examining temporary disposition and acquisition in peer-to-peer renting. Journal of Marketing Management, 31, 13101332.

Stanislawski, S., Yasushi S. \& Shuji O. (2013) Green Consumption and the Theory of Planned Behavior in the Context of Post-Megaquake Behaviors in Japan. Advances in Consumer Research. 41, 321-325.

Van Alstyne, M., Parker, G. \& Choudary, S. (2016) Pipelines, Platforms, and the New Rules of Strategy, Harvard Business Review. 
Watkins, R., Denegri-Knott, J. \& Molesworth, M. (2016) The relationship between ownership and possession: observations from the context of digital virtual goods. Journal of Marketing Management, 32, 44-70.

Yunhi K. \& Heesup H. (2010) Intention to pay conventional-hotel prices at a green hotel - a modification of the theory of planned behavior. Journal of Sustainable Tourism, 18, 997-1014. 
Table 1. Characteristics of the respondents

\begin{tabular}{ll}
\hline & $\begin{array}{l}\text { \% } \\
\text { (n =976) }\end{array}$ \\
\hline Gender & \\
Female & 59.9 \\
Male & 40.1 \\
Age & \\
Under 26 & 12.7 \\
26-35 & 12.4 \\
36-45 & 12.8 \\
46-55 & 14.0 \\
56-65 & 22.4 \\
Over 65 & 25.8 \\
Employment status & \\
Employed & 40.5 \\
Unemployed & 4.9 \\
Entrepreneur & 5.6 \\
Student & 8.9 \\
Retired & 35.8 \\
Parental leave & 1.8 \\
Other & 2.5 \\
Education & \\
\hline Primary school & 16.2 \\
Vocational school & 36.7 \\
Upper secondary school & 13.4 \\
University/ polytechnic degree & 29.1 \\
Academic post graduate degree & 4.6 \\
Income quartile & \\
1st (lowest) 2900 $€$ or less & 34.4 \\
\hline 2nd 2901 - 3900 $€$ & 15.2 \\
3rd 3901 - 5900 $€$ & 27.1 \\
4th (highest) 5901 € or over & 23.3 \\
\hline & \\
\hline & \\
\hline
\end{tabular}


Table 2. Analysis of variance (ANOVA) regarding collaborative consumption attitude (CCA), subjective norm (SN), perceived behavioral control (PBC), price consciousness (PC) and collaborative consumption intention (CCI). Means, F-values and significance (p)

\begin{tabular}{|c|c|c|c|c|c|c|c|c|c|}
\hline & CCA & $\mathbf{S N}$ & & PBC & & PC & & CCI & \\
\hline \multirow[t]{2}{*}{ TOTAL } & 5.36 & 4.44 & & 4.29 & & 4.16 & & 4.08 & \\
\hline & F (sig.) & & $\mathrm{F}$ (sig.) & & F (sig.) & & F (sig.) & & F (sig.) \\
\hline Age & $17.86 * * *$ & & $17.46^{* * *}$ & & $5.85^{* * *}$ & & $9.45^{* * *}$ & & 19.72 *** \\
\hline Under 26 & 5.71 & 4.79 & & 4.20 & & 4.83 & & 4.38 & \\
\hline $26-35$ & 6.00 & 5.21 & & 4.61 & & 4.28 & & 5.01 & \\
\hline $36-45$ & 5.86 & 4.85 & & 4.60 & & 3.90 & & 4.52 & \\
\hline $46-55$ & 5.47 & 4.46 & & 4.28 & & 4.00 & & 4.18 & \\
\hline $56-65$ & 5.34 & 4.42 & & 4.52 & & 4.06 & & 4.05 & \\
\hline Over 65 & 4.69 & 3.82 & & 3.95 & & 4.11 & & 3.37 & \\
\hline Gender & $5.14^{*}$ & & 28.46 *** & & 1.13ns & & 2.3ns & & $7.49 * *$ \\
\hline Female & 5.45 & 4.65 & & $(4.26)$ & & $(4.21)$ & & 4.20 & \\
\hline Male & 5.23 & 4.14 & & $(4.35)$ & & $(4.09)$ & & 3.91 & \\
\hline Employment & $14.14^{* * *}$ & & $12.01 * * *$ & & $4.26 * * *$ & & $9.65 * * *$ & & $17.63^{* * *}$ \\
\hline Employed & 5.66 & 4.71 & & 4.48 & & 4.05 & & 4.45 & \\
\hline Unemployed & 5.38 & 4.31 & & 4.44 & & 4.59 & & 4.24 & \\
\hline Entrepreneur & 5.54 & 4.56 & & 4.52 & & 3.45 & & 3.73 & \\
\hline Student & 5.81 & 4.89 & & 4.41 & & 4.77 & & 4.46 & \\
\hline Parental leave & 6.38 & 5.62 & & 4.62 & & 4.60 & & 5.91 & \\
\hline Retired & 4.82 & 3.96 & & 4.01 & & 4.15 & & 3.50 & \\
\hline 'Other' & 5.58 & 4.37 & & 4.06 & & 4.35 & & 4.04 & \\
\hline Education & $10.69 * * *$ & & $7.78 * * *$ & & $0.74 n s$ & & $4.04^{* *}$ & & $4.36 * *$ \\
\hline Primary & 4.90 & 4.12 & & $(4.22)$ & & 4.35 & & 3.78 & \\
\hline Vocational & 5.19 & 4.35 & & $(4.31)$ & & 4.13 & & 4.06 & \\
\hline Upper secondary & 5.53 & 4.62 & & $(4.31)$ & & 4.29 & & 4.01 & \\
\hline University" & 5.76 & 4.76 & & $(4.36)$ & & 4.14 & & 4.37 & \\
\hline
\end{tabular}




\begin{tabular}{|c|c|c|c|c|c|}
\hline Post graduate & 5.24 & 3.87 & $(4.01)$ & 3.59 & 3.73 \\
\hline $\begin{array}{l}\text { Income } \\
\text { quartile }\end{array}$ & 3.49* & $0.75 n s$ & $1.26 \mathrm{~ns}$ & $14.65^{* * *}$ & $(0.60) n s$ \\
\hline $1^{\text {st }}$ (low) & 5.26 & $(4.41)$ & $(4.29)$ & 4.48 & $(4.05)$ \\
\hline $2^{\text {nd }}$ & 5.17 & $(4.37)$ & $(4.31)$ & 4.03 & $(4.06)$ \\
\hline $3^{\text {rd }}$ & 5.40 & $(4.41)$ & $(4.21)$ & 4.12 & $(4.06)$ \\
\hline $4^{\text {th }}$ (high) & 5.61 & $(4.57)$ & $(4.46)$ & 3.84 & $(4.22)$ \\
\hline
\end{tabular}

Note: The scales for CCA, SN, PBC, PC and CCI range from 1 to 7. Ns=not significant. When there was no or very little statistical significance, the means are presented in parenthesis. ${ }^{*} \mathrm{p}<0.05$; ${ }^{* *} \mathrm{p}<0.01 ;{ }^{* * *} \mathrm{p}<0.001, \hat{\mathrm{r}}=0.05-0.10$.

") This category includes those having either university or polytechnic degree. 
Table 3. Regression analysis on collaborative consumption intention (CCI), collaborative consumption attitude (CCA), subjective norm (SN), perceived behavioral control (PBC), price consciousness (PC), standardized beta coefficients, Fvalue, sig

\begin{tabular}{|c|c|c|c|c|}
\hline & $\begin{array}{r}\text { CCI } \\
\text { Unadjusted } \\
\text { main effects }\end{array}$ & $\begin{array}{r}\text { CCI } \\
\text { Model } 1\end{array}$ & $\begin{array}{r}\text { CCI } \\
\text { Model } 2\end{array}$ & $\begin{array}{r}\text { CCI } \\
\text { Model } 3\end{array}$ \\
\hline CCA & $\begin{array}{r}0.526 \\
(\mathrm{~F}=365.49 * * *) \\
\mathrm{R}=27.6)\end{array}$ & 0.307 & 0.348 & 0.518 \\
\hline SN & $\begin{array}{r}0.549 \\
\left(\mathrm{~F}=413.53^{* * *}\right. \\
\mathrm{R}=30.1)\end{array}$ & 0.367 & & \\
\hline PBC & $\begin{array}{r}0.549 \\
\left(\mathrm{~F}=410.16^{* * *}\right. \\
\mathrm{R}=30.1)\end{array}$ & & 0.386 & \\
\hline PC & $\begin{array}{r}0.172 \\
\left(\mathrm{~F}=28.44^{* * *}\right. \\
\mathrm{R}=2.8)\end{array}$ & & & 0.107 \\
\hline $\mathbf{R}^{2} 100^{*}$ & & 36.2 & 39.3 & 29.1 \\
\hline Sig. F & & $270.99 * * *$ & $307.06 * * *$ & $190.66^{* * *}$ \\
\hline
\end{tabular}

